\title{
Corticospinal direct response in humans: identification of the motor cortex during intracranial surgery under general anaesthesia
}

\author{
YOICHI KATAYAMA, TAKASHI TSUBOKAWA, SADAHIRO MAEJIMA, \\ TERUYASU HIRAYAMA, TAKAMITSU YAMAMOTO \\ From the Department of Neurological Surgery, Nihon University School of Medicine, Tokyo, Japan
}

SUMMARY The corticospinal direct (D) response to stimulation of the motor cortex exposed for intracranial surgery was recorded in 20 cases from wire electrodes inserted into the spinal epidural space. The $\mathrm{D}$ response was obtained from stimulation of restricted areas of the cerebral cortex, that is, the hand, trunk and thigh areas of the motor cortex. The D response was resistant to anaesthesia and unaffected by muscle relaxants. Thus, recordings of the $\mathrm{D}$ response are useful for identifying the location of the motor cortex during intracranial surgery under general anaesthesia.

In experimental animals, it has repeatedly been demonstrated that a corticospinal direct (D) response to stimulation of the motor cortex can be recorded from the lateral column of the spinal cord or the spinal epidural space. ${ }^{1-4}$ The corticospinal $D$ response is recorded only when the motor cortex is stimulated. ${ }^{1-4}$ Furthermore, unlike muscle responses to motor cortex stimulation, the corticospinal D response is resistant to surgical doses of anaesthetics ${ }^{1-4}$ and is unaffected by muscle relaxants. Thus, recordings of the corticospinal $\mathrm{D}$ response during intracranial surgery in humans would be of value for identifying the location of the motor cortex and thereby reducing neurological complications resulting from unnecessary damage to the motor cortex. It has recently been reported that the corticospinal D response can be recorded in humans ${ }^{5-7}$ to transcranial stimulation of the brain through the intact scalp. ${ }^{8-16}$ We summarise here our experience with recordings of the corticospinal $D$ response to stimulation of the exposed motor cortex in humans during intracranial surgery.

\begin{abstract}
Methods
The data analysed were obtained from 20 patients who showed no motor deficits before surgery. Recordings of the

Address for reprint requests: Yoichi Katayama, M.D., Ph.D., Department of Neurological Surgery, Nihon University School of Medicine, 30 Oyaguchi-Kamimachi, Itabashi-ku, Tokyo 173, Japan.
\end{abstract}

Received 31 March 1987 and in revised form 5 June 1987. Accepted 26 August 1987 corticospinal $\mathrm{D}$ response were performed in these patients for the purpose of identifying the motor cortex and protec ting it from possible surgical damage. All patients gavo informed consent for intraoperative recording of the corti cospinal D response. A pair of flexible, platinum wire elec trodes insulated except at their tip (Medtronic Co. M-8483 fig 1) were inserted into the epidural space of the cervical and/or upper thoracic vertebrae before surgery. The subjects were placed in the lateral position and 18-gauge Touh needles were inserted into the epidural space at the uppes thoracic level. Each electrode was inserted with a stylet through the Touhy needles and advanced to the appropriate position under X-ray control. The Touhy needles were then removed and the electrodes fixed with adhesive tape on the skin. The response was recorded monopolarly from the electrodes, with the reference electrodes placed at the paravertebral muscles, in response to stimulation of the motor cortex exposed during surgery. The scalp of the forehead was grounded.

During intracranial surgery, the motor cortex and other cortical areas were directly stimulated with multicontact plate electrodes (Medtronic Co. M-3586). The location of the motor cortex, however, could not be precisely defined by any methods other than recordings of the corticospinal D response under general anaesthesia. Thus, in the present study, attention was focused on whether the $D$ response was elicited from stimulation of clearly restricted areas of the cortex, as is the $\mathrm{D}$ response in experimental animals; whether such areas roughly corresponded to the location of the motor cortex estimated from bone landmarks by means of a method usually employed for intracranial surgery; and whether surgical damage to an area from which the D response was obtained caused motor deficits. The four electrodes were $5 \mathrm{~mm}$ in diameter and spaced $5 \mathrm{~mm}$ apart. These electrodes were designated $0,1,2$ and 3 , respectively, beginning arbitrarily from one end to the other. The response was 


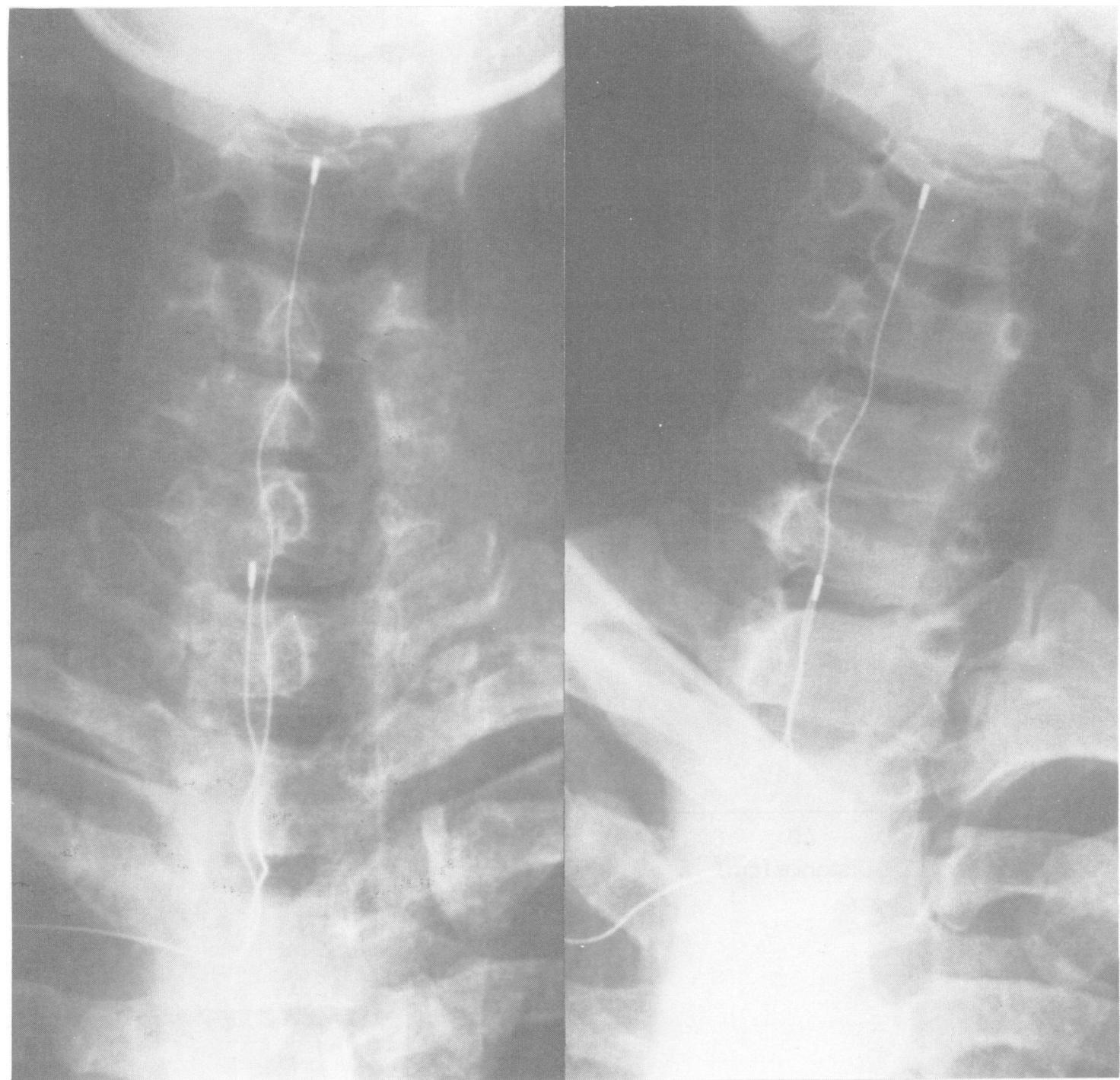

Fig 1 Radiographs showing electrode leads placed within the epidural space of the cervical spinal cord.

evoked by monopolar stimulation using one of these electrodes or bipolar stimulation with various pairs of electrodes. Thus, the interpolar distance for bipolar stimulation varied from 10 to $30 \mathrm{~mm}$. Stimuli were applied as monophasic square wave pulses of $0.2-0.5 \mathrm{~ms}$ duration delivered at $4 \mathrm{~Hz}$. Delivery of the stimuli was triggered by electrocardiograms. Signals from the electrodes were fed into an amplifier with a bandpass range of $5 \mathrm{~Hz}$ to $5 \mathrm{kHz}$ and averaged for 32-128 sweeps with a signal processor. Electroencephalograms were always monitored during recording of the responses, and were repeatedly recorded after the surgery.

\section{Results}

A response having a large negative wave (N1) preceded by a small positive wave (P1) (fig 2a) was invariably recorded from the spinal epidural space to stimulation of restricted areas of the cortex, which roughly corresponded to the location of the motor cortex estimated from bone landmarks (see below). Neither convulsive seizures nor epileptic discharges were induced on the electroencephalograms by the stimulation of the motor cortex. The response 
(a)

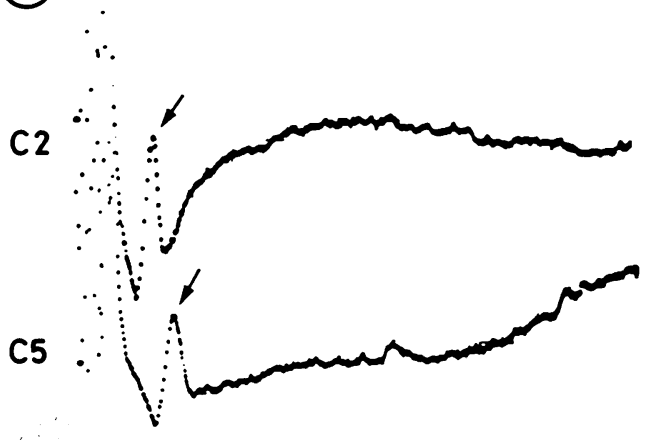

$\Delta$

Motor cortex stim.

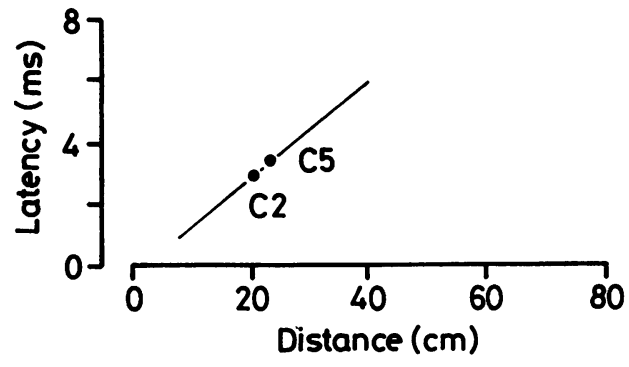

(b)
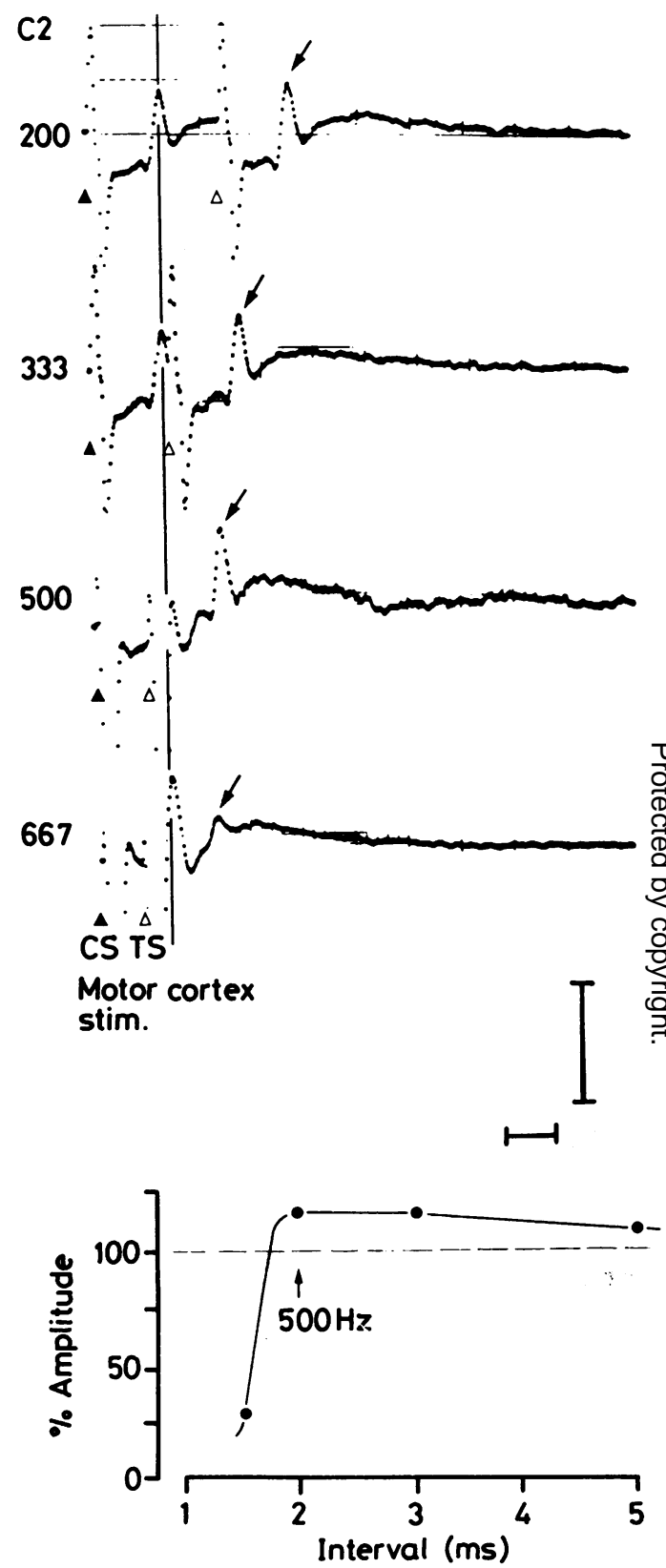

Fig 2 (a) Representative examples of responses recorded from the spinal epidural space (C2 and C5 levels) to stimulation of the exposed motor cortex. An upward deflection corresponds to negativity. Arrows indicate the N1 wave. Note that the amplitude of the PI-NI response decreases and the duration increases as the recording site is moved caudally. Two recording sites are also plotted with the stimulation-recording distance on the abscissa and the latency on the ordinate. (b) Effects of double pulse stimulation with various interstimulus intervals $(200-667 \mathrm{~Hz})$ on responses recorded from the spinal epidural space (C2 level) to stimulation of the motor cortex. Arrows indicate the NI wave in response to test stimulation. CS, conditioning stimulation; TS, test stimulation. Changes in percent values for the amplitude as compared with the response to single pulse stimulation (an average of records from 4 cases) are also shown in relation to interstimulus interval. Changes within 10\% cannot be evaluated with precision because of superimposed baseline changes. Calibrations: $2 \mathrm{~ms} 10 \mu \mathrm{V}$. 
Table Peak latency and conduction velocity of the NI response

\begin{tabular}{|c|c|c|c|c|}
\hline \multirow[b]{2}{*}{ Patient } & \multicolumn{2}{|c|}{ Peak latency $(\mathrm{ms})^{*}$} & \multirow[b]{2}{*}{ Distance ( $\mathrm{mm}$ ) between 2 rec. sites } & \multirow[b]{2}{*}{ Conduction velocity $(\mathrm{m} / \mathrm{s})$} \\
\hline & rostral rec. site & caudal rec. site & & \\
\hline $\begin{array}{l}1 \\
2 \\
3 \\
4 \\
5\end{array}$ & $\begin{array}{l}2.83 \\
2.90 \\
2.31 \\
3.53 \\
3.09\end{array}$ & $\begin{array}{l}3 \cdot 39 \\
3 \cdot 41 \\
2 \cdot 62 \\
4 \cdot 10 \\
3 \cdot 61\end{array}$ & $\begin{array}{l}28 \\
35 \\
21 \\
33 \\
39\end{array}$ & $\begin{array}{l}50 \\
69 \\
68 \\
57 \\
75\end{array}$ \\
\hline
\end{tabular}

*Values to the $\mathrm{N} 1$ response at maximum stimulation intensity.

was recorded regardless of whether the recording electrodes were placed dorsally or dorsolaterally to the spinal cord. These two waves could not be separated from each other on the basis of threshold and refractory period. As the recording site was moved caudally, the latency of the P1-N1 response increased and the amplitude decreased (fig 2a). The response also became gradually dispersed at lower levels (fig 2a). The difference in peak latency of the N1 wave over the known distance between two recording sites was used to calculate the conduction velocity (fig $2 a$ ). The calculated conduction velocity was within the range 50 to $75 \mathrm{~m} / \mathrm{s}$ (table). The $\mathrm{Pl}-\mathrm{N} 1$ response followed double pulse stimulation with interstimulus intervals of more than $500 \mathrm{~Hz}$ (fig $2 \mathrm{~b}$ ). Slight facilitation $(5-15 \%)$ of the P1-N1 response to submaximal stimulation (approximately 50\% maximal response) occurred with an antecedent conditioning stimulation with interstimulus intervals ranging from 100 to $500 \mathrm{~Hz}$ (fig 2b).

The lowest intensity for evoking the P1-N1 response was as low as $2 \mathrm{~mA}$, if the stimulation electrodes were appropriately placed on the motor cortex (see below). As the stimulation intensity was raised, the amplitude increased and then became saturated at certain levels of intensity (fig $3 a$ and $3 b$ ). It was also found that, as the stimulation intensity was raised, the latency decreased and then became constant with the stimulation intensity over certain levels (fig 3a and $3 \mathrm{~b}$ ). With an interpolar distance of $30 \mathrm{~mm}$ for bipolar stimulation, the maximal decrease in latency was $0.28 \mathrm{~ms}$ (fig $3 \mathrm{~b}$ ). The conduction velocity calculated from the latency differences between two recording sites, however, revealed no change.

For delineating the extent of stimulation sites from which the P1-N1 response was obtained, monopolar stimulation naturally provided better spatial resolution. The threshold of the $\mathrm{P} 1-\mathrm{N} 1$ response to monopolar stimulation with anodal currents was generally lower than that with cathodal currents. However, the response to monopolar stimulation during intracranial surgery was often unstable in amplitude and threshold during the course of surgery and was sometimes associated with uncontrollable artifacts, presumably due to large changes in impedance of current (a)

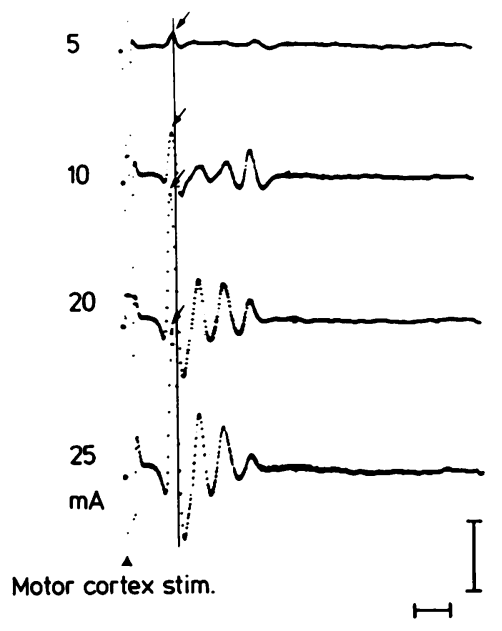

(b)
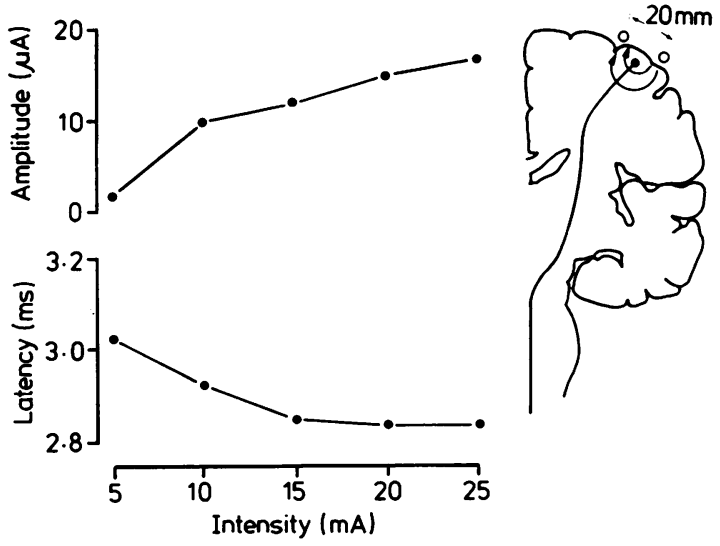

Fig 3 (a) Representative examples of responses recorded from the spinal epidural space to stimulation of the exposed motor cortex with various stimulation intensities (5-25 $\mathrm{mA}$ ). Arrows indicate the NI wave. Note the changes in amplitude and latency. N2,N3 and N4 waves are also seen with a high stimulation intensity $(10-25 \mathrm{~mA})$. (b) Changes in amplitude and latency are shown in relation to stimulation intensity. Interpolar distance of stimulation electrodes: $20 \mathrm{~mm}$.

Calibrations: $2 \mathrm{~ms} ; 10 \mu \mathrm{V}$. 
(a)

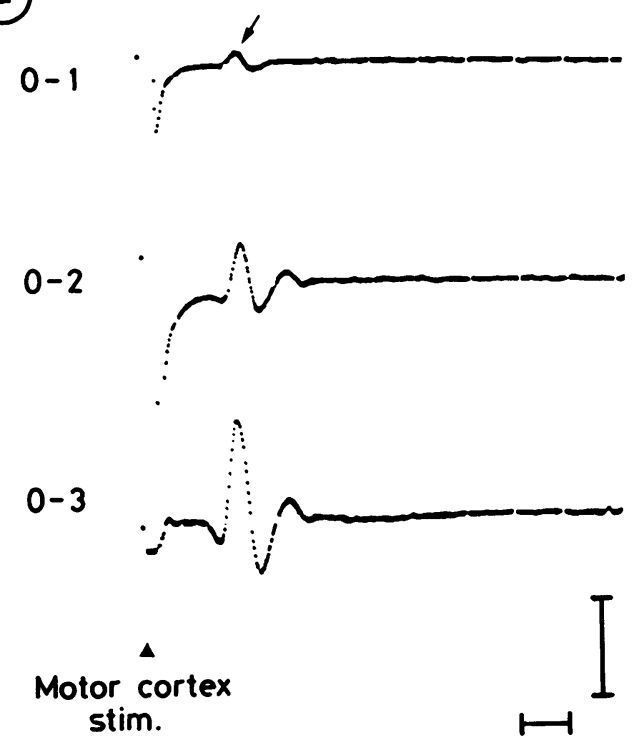

(b)
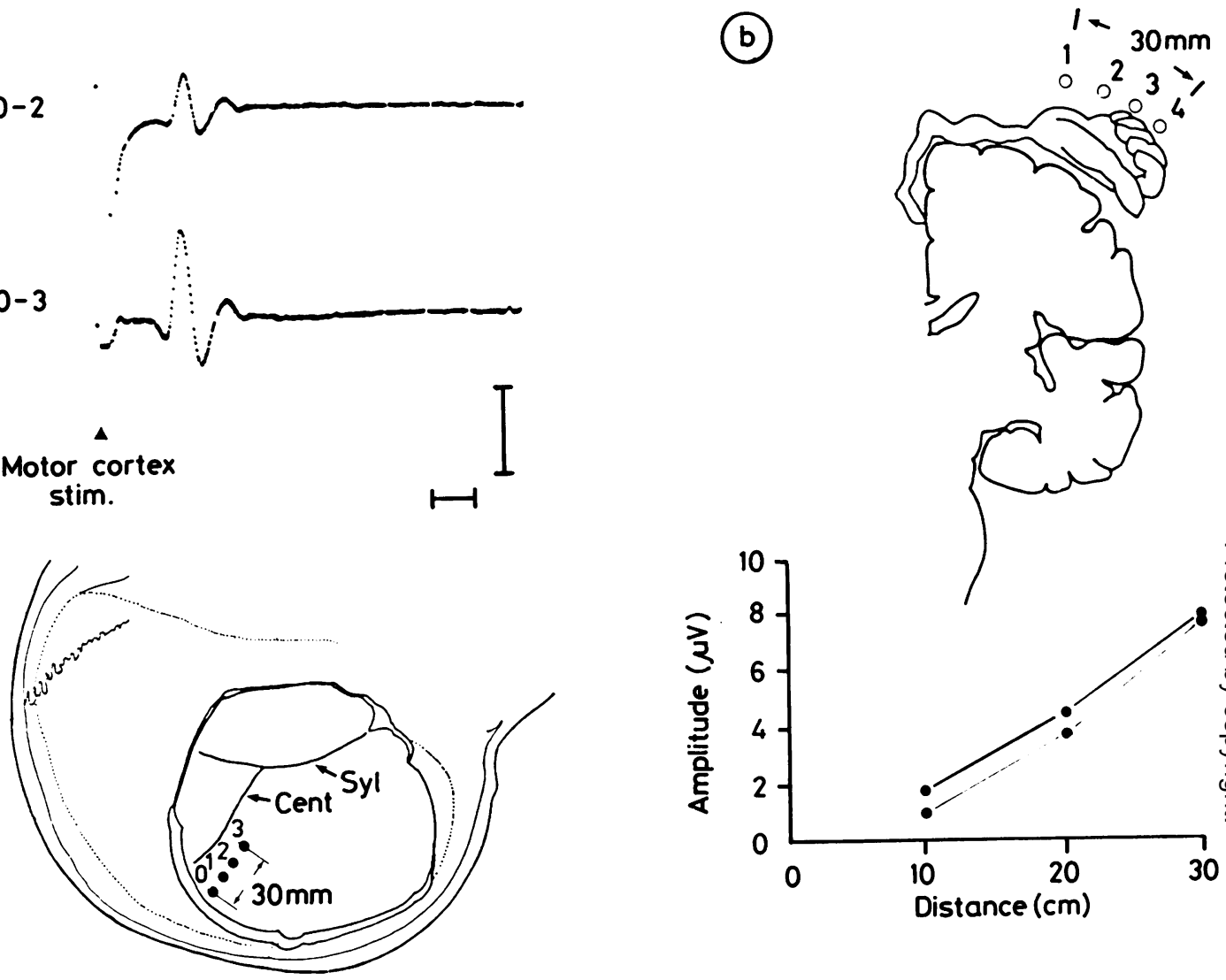

Fig 4 (a) Representative examples of responses recorded from the spinal epidural space to stimulation of the exposed motor cortex with various interpolar distances of the stimulation electrodes $(10-30 \mathrm{~mm})$. The arrow indicates the NI wave. Note the progressive increase in amplitude with a longer interpolar distance. Stimulation intensity: $5 \mu v$. (b) Changes in amplitude are shown in relation to interpolar distances of the stimulation electrodes. Calibrations: $2 \mathrm{~ms} ; 10 \mu \mathrm{V}$.

pathways induced by various surgical procedures. We, therefore, attempted to record the P1-N1 response with bipolar stimulation as well. It was difficult to obtain clear responses with interpolar distances of less than $10 \mathrm{~mm}$ for stimulation. In contrast, a longer interpolar distance of more than $10 \mathrm{~mm}$ clearly produced the $\mathrm{P} 1-\mathrm{N} 1$ response (fig $4 \mathrm{~A}$ ). At the same level of stimulation intensity, the longer interpolar distance produced a larger P1-N1 response. When both poles were placed on the motor cortex, the amplitude remained approximately the same after reversing the polarity of stimulation (fig $4 \mathrm{~b}$ ) and stimulation artifacts could be removed with a signal aver- aging technique by applying anodal currents alternately to one and then the other pole of the stimulation electrodes (fig 5). Such a technique, however, was rarely necessary when the patients were appropriately grounded. When only one pole of the stimulation electrodes was placed on the motor cortex, the amplitude was slightly larger with the anode rather than the cathode applied to the motor cortex.

With an interpolar distance of $10 \mathrm{~mm}$, the P1-N1 response was obtained only from stimulation of restricted areas of the cortex even employing a high stimulation intensity (fig 6). The focus giving the response with an interpolar distance of $10 \mathrm{~mm}$ 
C5
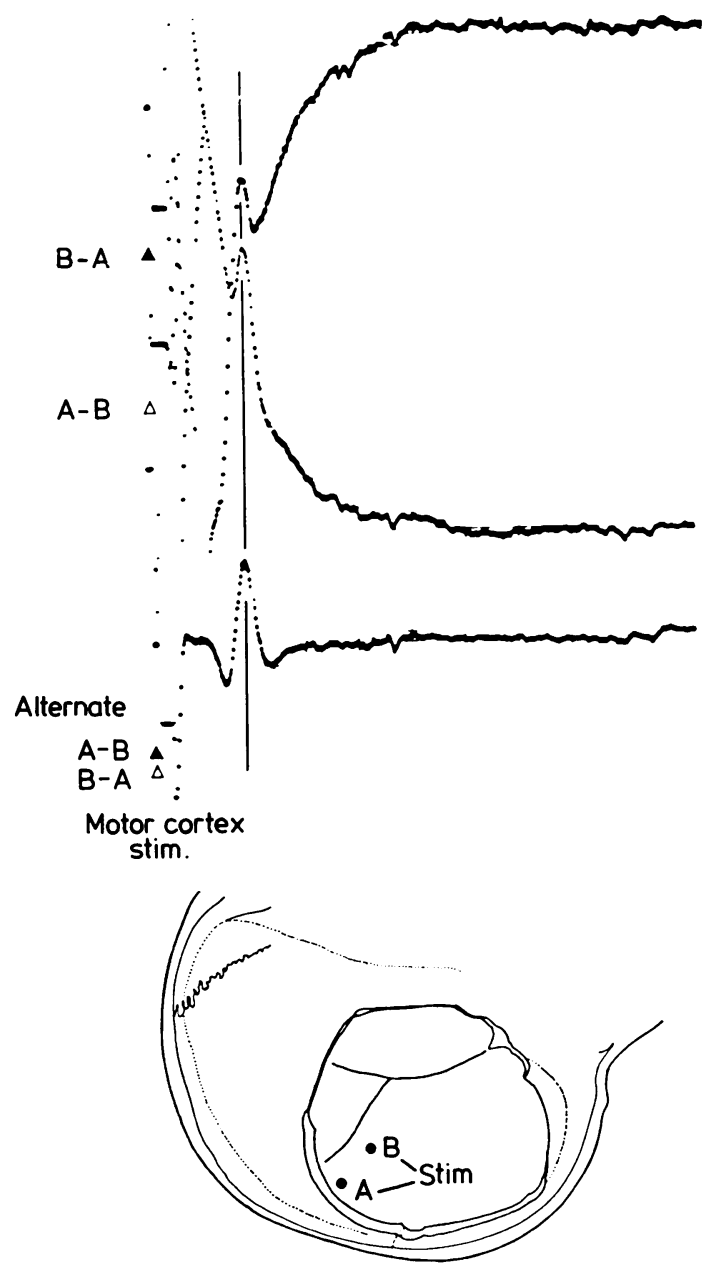

Fig 5 Representative examples of records containing large stimulation artifacts. Since both poles of the stimulation electrodes were placed appropriately on the motor cortex, the amplitude of the recorded responses remains approximately the same after reversing the polarity for stimulation. In such a case, stimulation artifacts can be removed by applying anodal currents alternately using $a$ signal averaging technique.

roughly corresponded to the motor cortex within areas $0-8 \mathrm{~cm}$ lateral to the midline, that is, the hand, trunk and thigh areas, as estimated from bone landmarks (fig 6). Stimulation of the medial motor cortex was not examined. When the hand area was stimulated with an interpolar distance of $10 \mathrm{~mm}$, the P1-N1 response was recorded only from the cervical level. Even with an interpolar distance of $30 \mathrm{~mm}$, the P1-N1 response was recorded only when at least one pole was placed precisely on or very close to the motor strip defined with interpolar distance of $10 \mathrm{~mm}$ for stimulation (fig 6). In three patients in whom surgical damage was caused to the areas delineated in this way, apparent motor deficits resulted after surgery. In contrast, remaining patients in whom surgical damage to these areas was avoided did not show apparent motor deficits.

The P1-N1 response was recorded independently of the depth of anaesthesia, and was relatively resistant to the physical condition of the motor cortex. Several negative waves (N2, N3 and N4) were sometimes seen with a high stimulation intensity following the initial $\mathrm{P} 1-\mathrm{N} 1$ response (fig 3a), but these later responses were vulnerable to changes in the physical condition of the cortex and the depth of anaesthesia. The later responses were dependent also on the modality of stimulation.

In three cases, the corticospinal responses to stimulation with electrodes placed in the cranial epidural space overlying the motor cortex were recorded after surgery without anaesthesia and muscle relaxants. In such recordings, the initial $\mathrm{P} 1-\mathrm{N} 1$ response followed by several negative waves and large muscle responses originating from the reference electrode placed in the paravertebral muscles were observed (fig 7). Progressive administration of thiopental (50-250 mg, IV) clearly attenuated the later waves (N2, N3 and N4), as well as the muscle responses (fig $7 \mathrm{a}$ and $\mathrm{b}$ ). In contrast, the initial $\mathrm{P} 1-\mathrm{N} 1$ response showed only slight depression in amplitude (fig 7a and b). In no instances did we encounter unfavourable side effects such as convulsive seizures or epileptic discharges on the electroencephalograms.

\section{Discussion}

Since the initial Pl and Nl waves recorded in the present study could not be separated from each other on the basis of threshold and refractory period, these two waves are considered more likely to represent a single synchronous impulse approaching and arriving at the recording site, respectively. The large and synchronous shape of the response suggested that the $\mathrm{P} 1-\mathrm{N} 1$ response is a volley mediated by a simple fibre tract without intervening synapses. Several lines of evidence supported such an interpretation. First, it was demonstrated that the $\mathrm{P} 1-\mathrm{N} 1$ response is capable of following double pulse stimulation with interstimulus intervals of more than $500 \mathrm{~Hz}$. Second, only slight facilitatory effects of double pulse stimulation were observed (see below). Finally the P1-N1 response, in contrast to the later $\mathrm{N} 2, \mathrm{~N} 3$ and $\mathrm{N} 4$ 

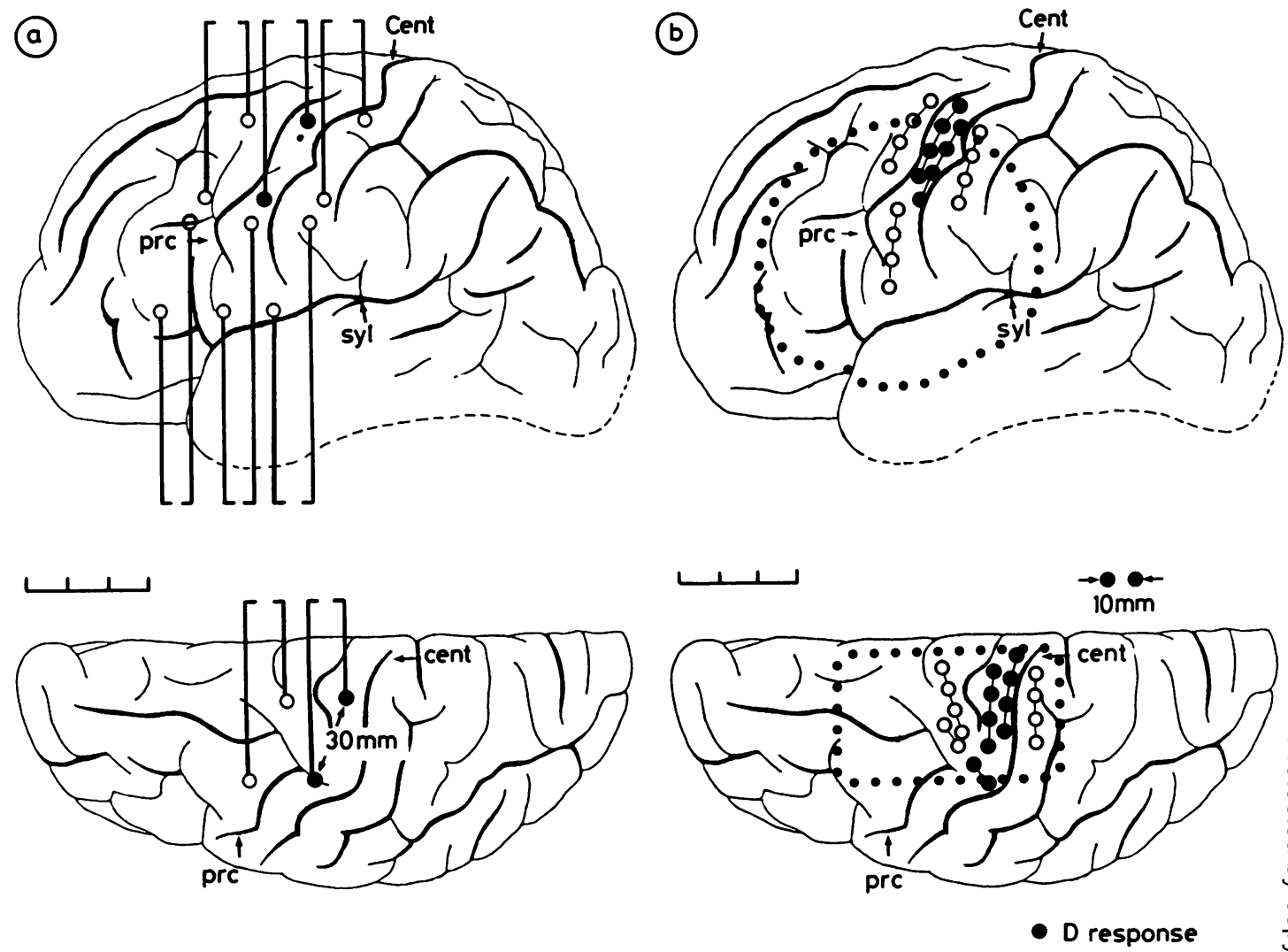

Fig 6 Focus of stimulation giving responses in the spinal epidural space. (a) Stimulation with an interpolar distance of $30 \mathrm{~mm}$. A pair of solid dots indicates a stimulation site giving responses. A pair of open circles indicates stimulation sites giving no response. (b) Small circles indicate foci giving responses even with an interpolar distance of $10 \mathrm{~mm}$ for stimulation Large circles indicate foci giving responses with an interpolar distance of $20 \mathrm{~mm}$ or more for stimulation. Areas encircled with dots indicate the extent of craniotomy. cent = central sulcus; prc = precentral sulcus; syl = Sylvian sulcus. Scale: $10 \mathrm{~mm}$.

responses, was found to be clearly resistant to surgical doses of anaesthetics. These observations are all consistent with the interpretation that the P1-N1 response is not a synaptically mediated potential.

The $\mathrm{Pl}-\mathrm{N} 1$ response is limited to stimulation of restricted areas which roughly correspond to the location of the motor cortex estimated from bone landmarks. Furthermore, apparent motor deficits are seen only when surgical damage is caused to these areas. These findings indicate that a fibre tract mediating this response originates in the motor cortex. No fibre tract other than the corticospinal tract is known to have such a direct projection from the motor cortex to the spinal cord. There are many similarities between the $\mathrm{Pl}-\mathrm{N} 1$ response recorded in the present study and the corticospinal D response reported for experimental animals. ${ }^{1-4}$ The conduction velocity of the $\mathrm{P} 1-\mathrm{N} 1$ response, $50-75 \mathrm{~m} / \mathrm{s}$, is similar to that obtained for the corticospinal D response or corticospinal neurons of the cat and monkey. ${ }^{1-4,17-20}$ Because of the dispersion of the response at lower levels of the spinal cord, the conduction velocity estimated in the present study from peak latency must be little lower than the maximal conduction velocity estimated from the onset latency of the response. However, this difference appears to be minimal at the cervical level as compared with possible variabilities due to unavoidable inaccuracies in roentgenographic measurements of conduction distance. This range of conduction velocity is consistent with the conduction velocity for fast corticospinal neurons. ${ }^{21-23}$ The N2, $\mathrm{N} 3$ and $\mathrm{N} 4$ responses seen following the P1-N1 response in the present study resemble the indirect (I) responses reported for experimental animals. ${ }^{1-4}$ The 
(a)

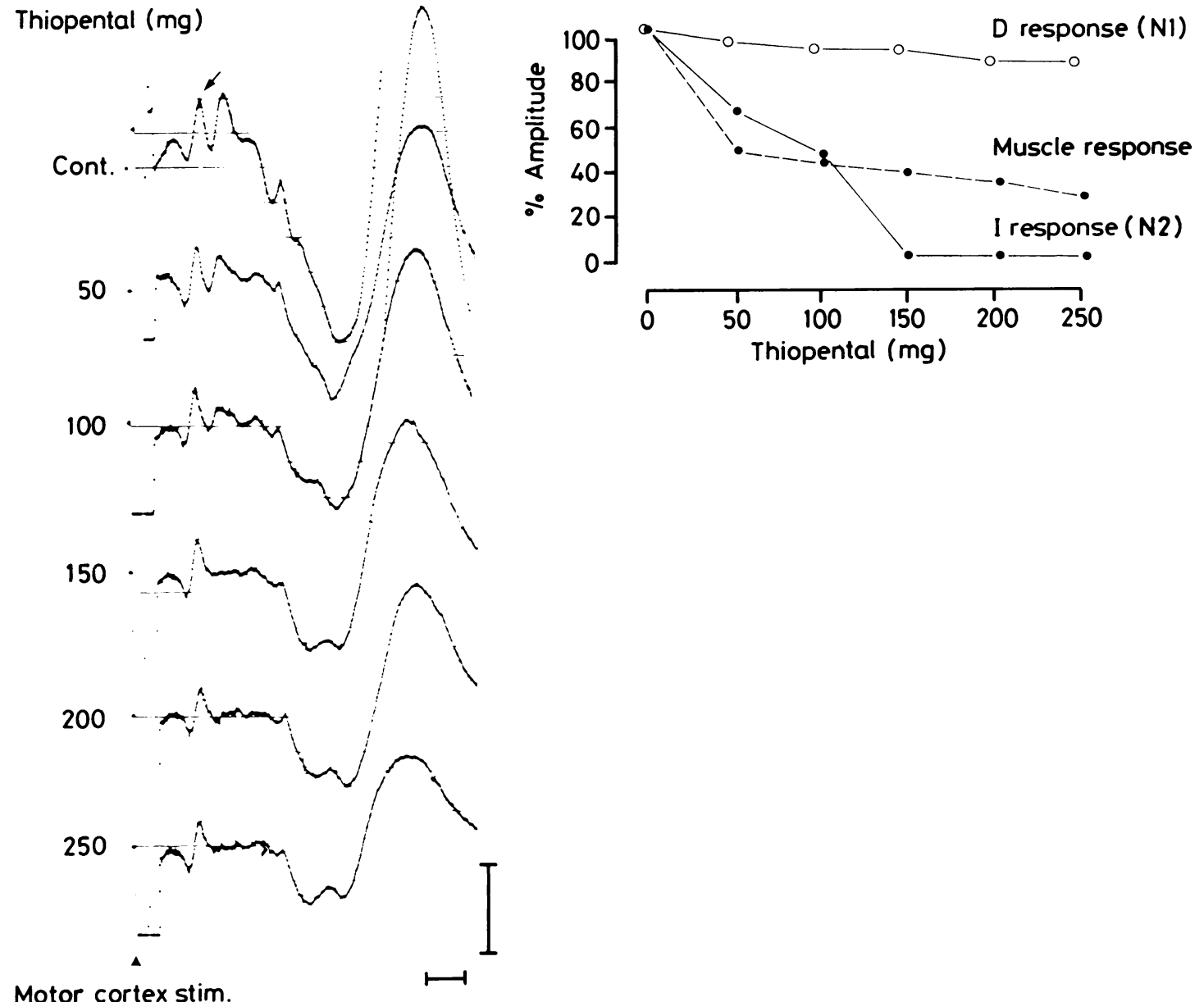

Fig 7 Representative responses recorded from the spinal epidural space to stimulation with electrodes placed in the cranial epidural space overlying the motor cortex without anaesthesia and muscle relaxants. The arrow indicates the N1 wave. Thiopental was progressively administered $(50-250 \mathrm{mg}, \mathrm{IV}$.). Note that large muscle responses are also recorded from the reference electrode placed in the paravertebral muscles following the N1 wave and several negative (N2, N3 and N4) waves In contrast to the N2, N3 and N4 waves and muscle responses, the NI wave is clearly resistant to thiopental. Calibrations: $2 \mathrm{~ms} ; 10 \mu \mathrm{V}$.

present results thus directly demonstrate that a corticospinal response equivalent to the $\mathrm{D}$ response described originally by Patton and Amassian ${ }^{1}$ for experimental animals can be recorded in humans as well. It has recently been reported that the corticospinal D response can be recorded in humans ${ }^{5-7}$ to transcranial stimulation of the motor cortex through the intact scalp. ${ }^{8-16}$ The data presented here are in agreement with the observation in these previous studies, ${ }^{5-7}$ especially that reported by Boyd et al, ${ }^{7}$ regarding the morphology, conduction velocity and other physiological features of the response.
The corticospinal $\mathrm{D}$ response has been considered to result from activation of the cell bodies and/or axons of corticospinal neurons rather than apical dendrite arborising in the superficial layer. ${ }^{14}$ The present study has demonstrated, in agreement with earlier studies on experimental animals, ${ }^{14}$ that slight facilitation of the corticospinal $D$ response can occur with an antecedent conditioning stimulation. The occurrence of facilitation suggests that the corticospinal $D$ response results at least in part from excitation of the cell bodies or initial segments of corticospinal neurons. However, it does appear that 
the corticospinal D response results largely from direct excitation of cortical or subcortical axons of corticospinal neurons, especially when higher levels of stimulation intensity are used. The present results showed that, as the stimulation intensity was raised, the latency of the corticospinal D response decreased. Since the conduction velocity calculated from the difference in latency between two recording sites did not change, the decrease in latency may have been due to spread of the stimulation currents to more distal parts of axons (see fig $3 b$ ). Similar observation has been reported in humans with transcranial brain stimulation. ${ }^{7}$

The finding that the corticospinal $\mathrm{D}$ response in humans is limited to the motor cortex provides a means of identifying the motor cortex during intracranial surgery under general anaesthesia. The traditional concept of the motor cortex has been developed on the basis of studies which employed stimulation of the cortical surface to evoke muscle movements. ${ }^{24-26}$ It has been shown by Asanuma et $\mathrm{al}^{26}$ in experimental animals that intracortical microstimulation can permit more discrete mapping than that obtained with surface stimulation. ${ }^{2326}$ However, mapping of the motor cortex with evoked muscle movements is not easy under general anaesthesia with the use of muscle relaxants. In contrast, the corticospinal D response is resistant to the usual doses of anaesthetics and is unaffected by muscle relaxants. This is clearly one advantage of identifying the motor cortex from the corticospinal $D$ response under general anaesthesia. While corticospinal neurons as detected by retrograde axonal transport of horseradish peroxidase are also seen in other areas of the cortex in the monkey, the most dense labelling with horseradish peroxidase occurs in the motor cortex ${ }^{27}$ and fast corticospinal neurons are substantially restricted to the motor cortex. The corticospinal $D$ response recorded from the spinal epidural space may be attributable to synchronous activation of such dense corticospinal projections originating in the motor cortex.

In order to identify the location of the motor cortex with the $\mathrm{D}$ response, monopolar stimulation with anodal current is apparently preferable. A large number of investigations in experimental animals have indicated that anodal current, rather than cathodal current, more easily activates deeply located initial segments or axons of corticospinal neurons from which the D response initiates. ${ }^{4}$ However, monopolar stimulation during intracranial surgery appears to be associated with considerable changes in impedance of current pathways related to various surgical procedures, which result in unstable recordings and sometimes uncontrollable artifacts. In contrast, bipolar stimulation provides constant responses with- out large artifacts. It is very difficult to obtain clear responses with bipolar stimulation with interpolar distance of less than $10 \mathrm{~mm}$ in humans. Similar observation has been made in experimental animals. It has been argued that bipolar stimulation with such a short interpolar distance produces a current which spreads tangentially, and preferentially activates superficially located neural elements. ${ }^{4}$ In contrast, responses obtained with bioplar stimulation with interpolar distance of more than $10 \mathrm{~mm}$ may be considered to be the sum of responses to monopolar stimulation with anodal and cathodal currents. ${ }^{4}$ Furthermore, the present study did show that the focus giving the corticospinal $\mathrm{D}$ response with an interpolar distance of $10 \mathrm{~mm}$ for stimulation is restricted to the hand, trunk and thigh areas of the motor cortex (see fig 6b). ${ }^{2425}$ Even with an interpolar distance of $30 \mathrm{~mm}$ for stimulation, the corticospinal $\mathrm{D}$ response is recorded only when at least one pole is placed precisely on or very close to these areas. Thus, an interpolar distance of $10-30 \mathrm{~mm}$ for stimulation appears to provide practically useful information concerning the location of the motor cortex.

The motor cortex may be displaced in cases with intracranial space-taking lesions. The functioning motor cortex may be displaced also in cases with arteriovenous malformations which involve the

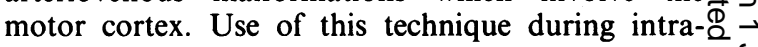
cranial surgery should, therefore, help to reduce neurological complications resulting from unnecessary damage to the motor cortex in such cases.

\section{References}

1 Patton HD, Amassian VE. Single- and multiple-unit analysis of cortical stage of pyramidal tract activation. $J$ Neurophysiol 1954;17:345-63.

2 Levy WJ, McCaffrey M, York D, Tanzer F. Motor evoked poten tials from transcranial stimulations of the motor cortex in cats. Neurosurgery 1984;15:214-27.

3 Katayama Y, Tsubokawa T, Sugitani M, Maejima S, Hirayama T. Assessment of spinal cord injury with multimodality evoked spinal cord potentials. Part 1 Localization of lesions in experimental spinal cord injury. Neuro-Orthopedics 1986;1:130-41.

4 Amassian VE, Stewart M, Quirk GJ, Rosenthal JL. Physiological basis of motor effects of transient stimulus to cerebral cortex. Neurosurgery 1987;20:74-93.

5 Levy WJ, York DH, McCaffrey M, Tanzer F. Motor evoked potentials from transcranial stimulation of the motor cortex in humans. Neurosurgery 1984;15:287-302.

6 Tsubokawa T, Yamamoto T, Hirayama T, Maejima S, Katayama Y. Clinical application of corticospinal evoked potentials as a monitor of pyramidal function. Nihon Univ J Med 1986;28:27-37.

7 Boyd S, Rothwell JC, Cowan JMA, et al. A method of monitoring function in corticospinal pathways during scoliosis surgery with a note on motor conduction velocities. $J$ Neurol Neurosurg Psychiatry 1986;49:251-7. 
8 Marsden CD, Merton PA, Morton HB. Maximal twitches from stimulation of the motor cortex in man. Proc Physiol Soc 1980;312:5

9 Marsden CD, Merton PA, Morton HB. Percutaneous stimulation of spinal cord and brain. Proc Physiol Soc J Physiol 1982;328:6.

10 Marsden CD, Merton PA, Morton HB. Direct electrical stimulation of corticospinal pathways through the intact scalp in human subjects. In: Desmedt JE, ed. Motor Control Mechanisms in Health and Disease. New York: Raven Press 1983:387-91.

11 Merton PA, Morton HB. Electrical stimulation of human motor and visual cortex through the scalp. Proc Physiol Soc J Physiol 1980;305:9-10.

12 Merton PA, Morton HB, Hill DK, Marsden C. Scope of a technique for electrical stimulations of human brain, spinal cord and muscles. Lancet 1982;ii:597-600.

13 Merton PA, Morton HB. Stimulation of the cerebral cortex in the intact human subject. Nature 1980;285:227.

14 Hassan NF, Rossini PM, Cracco RQ, Cracco JB. Unexposed motor cortex activation by low voltage stimuli, In: Morocutti C, Rizzo PA, eds. Evoked Potentials: Neurophysiological and Clinical Aspects. Amsterdam: Elsevier 1985;107-13.

15 Rossini PM, Marciani MG, Caramia M, Roma V, Zarola F. Nervous propagation along "central" motor pathways in intact man: Characteristics of motor responses to "bifocal" and "unifocal" spine and scalp non-invasive stimulation. Electroencephalogr Clin Neurophysiol 1985;61:272-86.

16 Rossini PM, Stefano ED, Stanzione P. Nerve impulse propagation along central and peripheral fast conducting motor and sensory pathways in man. Electroencephalogr Clin Neurophysiol 1985;61:320-34.
17 Lloyd DPC. The spinal mechanism of the pyramidal system in cats. J Neurophysiol 1941;4:525-46.

18 Brookhart J, Morris RE. Antidromic potential recordings from the bulbar pyramid of the cat. $J$ Neurosurg 1948;1:387-98.

19 Lance JW. Pyramidal tract in spinal cord of cat. J Neurophysiol 1954;17:253-70.

20 Philips CG, Porter R. Corticospinal Neurones. London: Academic Press 1977:268.

21 Takahashi K. Slow and fast groups of pyramidal tract cells and their respective membrane potentials. J Physiol (Lond) 1965; 28:908-24.

22 Deschenes L, Labelle A, Aandry P. Morphological characteristics of slow and fast pyramidal tract cells in the cat. Brain Res 1979;178:251-74.

23 Humphrey DR. Corticospinal systems and their control by premotor cortex, basal ganglia, and cerebellum. In: Rosenberg RN, Willis WD, eds. Clinical Neurosciences Vol 5: Neurobiology. New York: Churchill Livingstone 1983:547-87.

24 Rasmussen T, Penfield W. Further studies of the sensory and motor cerebral cortex of man. Fed Proc 1947;6:452-60.

25 Terzuolo CA, Adey WR. Sensorimotor cortical activities. In: Magoun HW, ed. Handbook of Physiology, Section 1: Neurophysiology Vol 2. Washington DC: American Physiological Society 1960:797-835.

26 Asanuma H. Recent developments in the study of the columnar arrangement of neurons within the motor cortex. Physiol Rev 1975;55:143-56.

27 Toyoshima K, Sakai H. Exact cortical extent of the origin of the corticospinal tract (CST) and the quantitative contribution to the CST in different cytoarchitectonic areas: A study with horseradish peroxidase in the monkey. $J$ Hirnforsch 1982;23:257-69. 